\title{
Access to the Heart - Evolution of surgical techniques
}

\author{
Jai Raman* \\ Department of Cardiovascular and Thoracic Surgery, Rush University Medical Center, 1725 W Harrison St, Chicago, Il 60612, USA
}

\begin{abstract}
Access to the heart and closure of the resultant incisions and wounds have been considered major impediments to the growth of cardiac surgery. Nevertheless, during the 1980s and 1990s, the sternotomy was the most commonly performed surgical access procedure in the world. We discuss the evolution of various techniques to allow access to the heart and surrounding structures. Methods of closure of these incisions are also highlighted as these techniques evolve.
\end{abstract}

\section{Introduction}

No mention of early cardiac surgery can be complete without the mention of Dr. Daniel Hale Williams, an African American surgeon in the South Side of Chicago. The big names in surgery in Europe, such as Paget and Billroth, had advice about the dangers of operating on the heart and suggested that anyone embarking on such an endeavor was foolhardy. Fortunately for us all, Dr. Williams operated successfully on the first patient with cardiac tamponade in 1893 [1]. The procedure performed on James Cornish, who was the victim of a bar-room brawl and had suffered a stab wound to the chest and the heart [2]. This was effected through a left thoracotomy with exposure of the pericardium and its contents. This procedure was attempted in a desperate attempt to save a patient who was declining steadily. This was done in the absence of X-rays, CTs, echocardiograms, electrocardiograms. Despite a recurrence of tamponade, which was successfully drained 21 days later through a second thoracotomy, the patient did well. The patient survived for 38 years, dying of a head wound from another bar fight in 1931! [3,4] (Figure 1).

In 1897, Ludwig Rehn of Frankfurt, Germany reported on 120 surgeries performed around the world for stab wounds on the heart with suture repair through thoracotomies with a $40 \%$ success [5].

The midline or median sternal osteotomy or sternotomy was first described in experimental animals, by Milton, in 1897. Since ventilators were not developed then, Milton was very satisfied by the fact that this

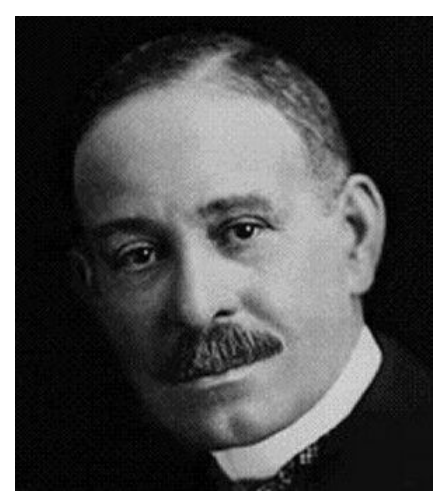

Figure 1. Dr. Daniel Hale Williams. incision could be safely achieved in a live goat, which then survived the procedure. He also noted that this provided great exposure to the heart [6]. Dr. Ormand Julian, a surgeon at the University of Illinois at Chicago popularized the median sternotomy for all cardiac operations. He subsequently moved to Rush Presbyterian Medical Center and used his prominence there to push this concept [7] (Figure 2).

Other prominent surgeons of the era reinforced the fact that this approach was less traumatic and provided access to all chambers of the heart along with the capability of connecting the patients to cardiopulmonary bypass [8]. Since then, this procedure gained prominence and rapidly became the most common approach to the heart. Indeed, the median or midline sternotomy is now the most commonly performed osteotomy or bone-breaking procedure in medicine. Sternotomies have been performed through bilateral submammary incisions to improve the cosmetic appearance [9].

Closure of the bone in these incisions was initially performed by cerclage using thick suture, typically \#5 Ticron or equivalent, as described by Dr. Julian. However, the perceived risk of infection in using a braided suture made surgeons move to using stainless steel

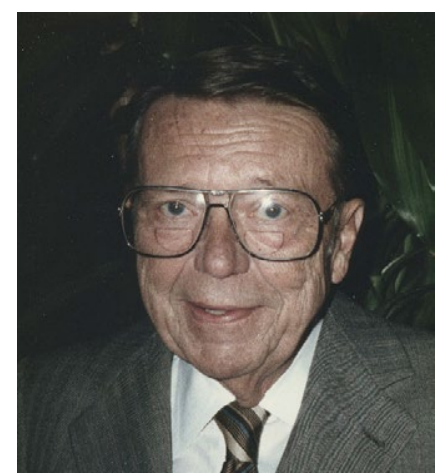

Figure 2. Dr.Ormand Julian.

Correspondence to: Jai Raman, Department of Cardiovascular and Thoracic Surgery, Rush University Medical Center,1725 W Harrison St, Chicago, Il 60612, USA, Tel: 1-773-9190088, Fax: 1-312-563 4388; E-mail: jairaman2462@gmail.com

Received: August 25, 2015; Accepted: September 02, 2015; Published: September 04, 2015 
wire. Sternal closure was typically achieved by simple wire cerclage. A variety of other techniques were used to close the sternum, such as figure of 8 wires, sternal bands, interlocking weaves of the wire, etc. These were performed in attempts to minimize the complications from sternotomy closure, which ranged from pain, dehiscence, and mal-union to deep sternal wound infections \& mediastinitis. Despite the sternotomy being used frequently and considered routine by most cardiac surgeons, the problems associated with it have caused a perception of a very invasive procedure. The infective complications following sternotomy, such as mediastinitis maybe lethal. Recovery after infective complications or improper union may cause significant long term disability and chronic pain.

Dr. Larry Gottlieb, an innovative plastic surgeon, at the University of Chicago, described the use of modified mandibular plates to salvage sternal closure in the setting of sternal wound infections [10]. Raman \& Song described the modification to this by advocating prophylactic sternal plating in the high-risk patient [11]. Indeed, this concept was studied in a randomized, controlled trial and showed better bone healing at 3 and 6 months, with lower post-operative pain in plated patients [12] (Figure 3).

Over the past 3 years, the concept of rigid plate fixation of the sternum has gradually expanded to multiple centers across the world, with the technology being used in Australia, China, Japan, India, Canada, Europe, and the US. The barrier to widespread adoption is still the cost of the plates and screws.

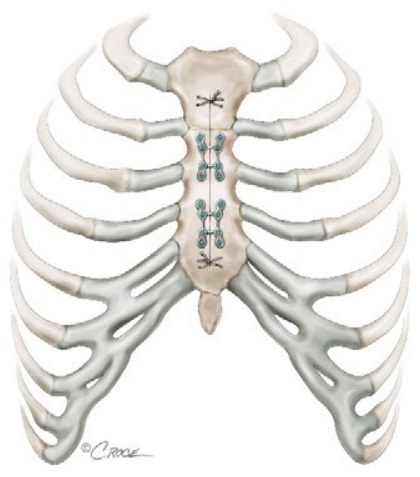

Figure 3. Schematic diagram depicting plate fixation of the sternum.

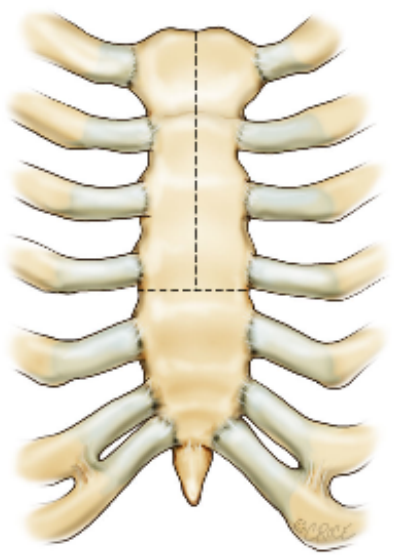

Figure 4a. Inverted ' $\mathrm{T}$ ' configuration for Ministernotomy.

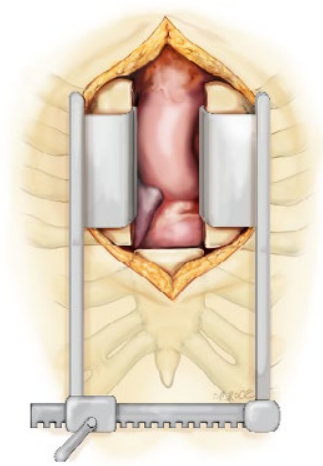

Figure 4b. Typical view of the aortic root and RVOT through mini-sternotomy.

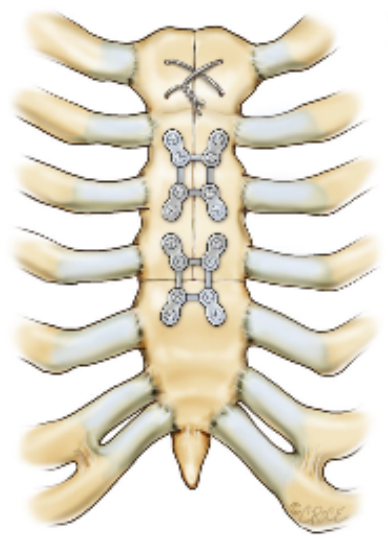

Figure 4c. Plate fixation of the Inverted ' $T$ ' mini-sternotomy.

\section{Mini-sternotomy approaches}

Various types of partial sternotomies have been used with significant success for a variety of indications [13]. Configurations such as inverted ' $T$ ', ' $J$ ', 'L' have been used to divide the upper half of the sternum, typically up to the $4^{\text {th }}$ interspace on one or both sides. The great advance in this instance again is the availability of rigid plate fixation which provides great stability and secure closure [14] (Figures $4 a-4 c)$.

Variations on the mini-sternotomy include the arrowhead modification, which allows extensive reconstruction of the aortic root, ascending aorta, aortic arch and the pulmonary artery [15].

\section{Thoracotomy approaches}

For many years, the standard procedure on the heart was a left minithoracotomy and a closed mitral valvotomy [16]. This procedure was developed in the 1950s and was still being performed into the late 1990s. The sternotomy then superseded this approach as cardiopulmonary bypass became the standard and more complex procedures were being performed on the heart.

Over the past 8-10 years, increased interest in minimally invasive approaches to the heart have encouraged the development of left minithoracotomy procedures for CABG and left ventricular epicardial lead implant procedures. Right minithoracotomy approaches have been developed with great success, for mitral valve procedures [17], tricuspid valve procedures [18] and aortic valve procedures. The 

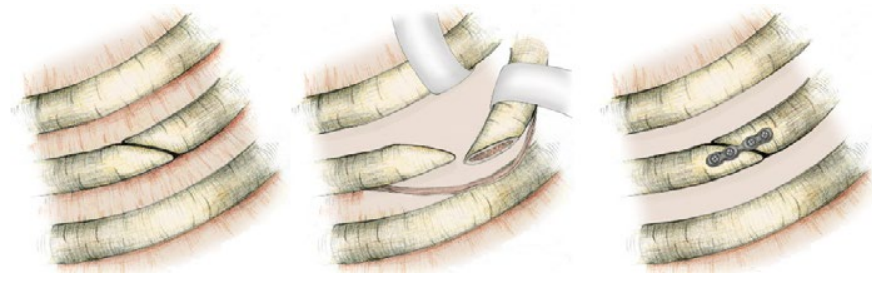

Figure 5. Steps of oblique osteotomy, to facilitate exposure and closure at the end with plate fixation.

exact location of each of these incisions may vary according to patient habitus, valve location, previous cardiac history and anatomical features (as detected by pre-operative or intra-operative imaging). Rib fixation of the osteotomies to facilitate better exposure, dramatically reduces post-operative pain in these patients [19] (Figure 5).

Clam-shell bilateral thoracotomies with transverse division of the sternum is used for bilateral sequential lung transplant procedures [20]. They have been used on occasion for complex reconstructions of the aorta from the aortic root to the descending thoracic aorta. This technique has a lot of applications in emergency department resuscitation and open cardiac massage [21]. Typically, these incisions are closed with multiple peri-costal sutures to approximate the ribs combined with either wire cerclage or rigid plate fixation of the sternal component.

\section{Conclusions}

A variety of access incisions have been described to access the heart. The move towards less invasive approaches has allowed surgeons to resurrect older incisions and develop new techniques to minimize pain and dramatically improve outcomes after heart surgery.

\section{Acknowledgement}

These beautiful illustrations are from the talented hands of Beth Croce and Nicole Cipriani, and I gratefully acknowledge their contributions.

\section{References}

1. Beatty WK (1971) Daniel Hale Williams: innovative surgeon, educator, and hospital administrator. Chest 60: 175-182. [Crossref]

2. Montague Cobb W (1944) Daniel Hale Williams - Pioneer and Innovator. J Natl Med Assoc 36: 158-159. [Crossref]

3. Dunn R (2015) The Man Who Touched His Own Heart: True Tales of Science, Surgery and Mystery. Little Brown \& Company.
4. Williams DH (1897) Stab wound of the Heart and Pericardium - Suture of the Pericardium - Recovery - Patient Alive Three Years Afterward. Medical Record 51:439.

5. Rehn L (1897) On Penetrating Cardiac Injuries and Cardiac Suturing. Archiv fur klinische Chirurgie 55: 315

6. Dalton ML, Connally SR (1993) Median sternotomy. Surg Gynecol Obstet 176: 615624. [Crossref]

7. Dalton ML, Connally SR, Sealy WC (1992) Julian's reintroduction of Milton's operation. Ann Thorac Surg 53: 532-533. [Crossref]

8. Gerbode F, Braimbridge MV, Melrose DG (1958) Median Sternotomy for Open Cardiac Surgery During Total Heart-Lung By-Pass. AMA Arch Surg 76: 821-824.

9. Odim J, Vyas R, Laks H, Alikhani A, Mehta U, et al. (2005) Redo submammary incision for median sternotomy and cardiac repair. Ann Thorac Surg 79: 163-167. [Crossref]

10. Gottlieb LJ, Pielet RW, Karp RB, Krieger LM, Smith DJ Jr, et al. (1994) Rigid internal fixation of the sternum in postoperative mediastinitis. Arch Surg 129: 489-493. [Crossref]

11. Song DH, Lohman RF, Renucci JD, Jeevanandam V, Raman J (2004) Primary sternal plating in high-risk patients prevents mediastinitis. Eur J Cardiothorac Surg 26: 367372. [Crossref]

12. Raman J, Lehmann S, Zehr K, De Guzman BJ, Aklog L, et al. (2012) Sternal closure with rigid plate fixation versus wire closure: a randomized controlled multicenter trial. Ann Thorac Surg 94: 1854-1861. [Crossref]

13. Phan K, Xie A, Tsai YC, Black D, Di Eusanio M, et al. (2015) Ministernotomy or minithoracotomy for minimally invasive aortic valve replacement: a Bayesian network meta-analysis. Ann Cardiothorac Surg 4: 3-14. [Crossref]

14. Raman J (2012) Rigid plate fixation promotes better bone healing after sternotomy. Semin Thorac Cardiovasc Surg24: 147-150. [Crossref]

15. Russo MJ, Gnezda J, Merlo A, Johnson EM, Hashmi M, et al. (2014) The Arrowhead Ministernotomy with Rigid Sternal Plate Fixation: A Minimally Invasive Approach for Surgery of the Ascending Aorta and Aortic Root. Minimally Invasive Surgery.

16. Tütün U, Ulus AT, Aksöyek AI, Hizarci M, Kaplan S, et al. (2003) The place of closed mitral valvotomy in the modern cardiac surgery era. J Heart Valve Dis 12: 585-591. [Crossref]

17. Benetti FJ, Rizzardi JL, Pire L, Polanco A (1997) Mitral valve replacement under video assistance through a minithoracotomy. Ann Thorac Surg 63: 1150-1152. [Crossref]

18. Peters WS, Stevens JH, Smith JA, Rosenfeldt FL, Siegel LC, et al. (1997) Minimally invasive right heart operations: techniques for bicaval occlusion and cardioplegia. Ann Thorac Surg 64: 1843-1845. [Crossref]

19. Raman J, Onsager D, Straus D (2010) Rib osteotomy and fixation: enabling technique for better minithoracotomy exposure in cardiac and thoracic procedures. $J$ Thorac Cardiovasc Surg 139: 1083-1085. [Crossref]

20. Mitilian D, Sage E, Puyo P, Bonnette P, Parquin F, et al. (2014) Lung Transplant Group. Techniques and results of lobar lung transplantations. Eur J Cardiothorac Surg 45: 365-369.

21. Puchwein P, Sommerauer F, Clement HG, Matzi V, Tesch NP, et al. (2015) Clamshel thoracotomy and open heart massage-A potential life-saving procedure can be taugh to emergency physicians: An educational cadaveric pilot study. Injury 46: 1738-1742. [Crossref]

Copyright: (C2015 Raman J. This is an open-access article distributed under the terms of the Creative Commons Attribution License, which permits unrestricted use, distribution, and reproduction in any medium, provided the original author and source are credited. 